\title{
Development of fetal movement between 26 and 36-weeks' gestation in response to vibro-acoustic stimulation
}

\author{
Marybeth Grant-Beuttler ${ }^{1 *}$, Laura M. Glynn ${ }^{2,3}$, Amy L. Salisbury ${ }^{4}$, Elysia Poggi Davis ${ }^{3,5}$, Carol Holliday ${ }^{3,6}$ \\ and Curt A. Sandman ${ }^{3}$ \\ ${ }^{1}$ Department of Physical Therapy, Crean School of Health and Life Sciences, Schmid College of Science and Technology, Chapman University, Orange, CA, USA \\ ${ }^{2}$ Crean School of Health and Life Sciences, Schmid College of Science and Technology, Chapman University, Orange, CA, USA \\ ${ }^{3}$ Department of Psychiatry and Human Behavior, University of California-Irvine, Orange, CA, USA \\ ${ }^{4}$ Department of Pediatrics, Women and Infants, Brown Center for the Study of Children at Risk, Brown University, Providence, RI, USA \\ ${ }^{5}$ Department of Pediatrics, University of California-Irvine, Irvine, CA, USA \\ ${ }^{6}$ Vanguard Center, National Children's Study, Irvine, CA, USA
}

\section{Edited by:}

Susan M. Rivera, University of California, USA

Reviewed by:

Moriah E. Thomason, Stanford University, USA

Teresa Mitchell, University of Massachusetts Medical School, USA

${ }^{*}$ Correspondence:

Marybeth Grant-Beuttler, Department of Physical Therapy, Chapman University, One University Drive, Orange, CA 92866, USA.

e-mail:beuttler@chapman.edu

\begin{abstract}
Background: Ultrasound observation of fetal movement has documented general trends in motor development and fetal age when motor response to stimulation is observed. Evaluation of fetal movement quality, in addition to specific motor activity, may improve documentation of motor development and highlight specific motor responses to stimulation. Aim: The aim of this investigation was to assess fetal movement at 26 and 36-weeks gestation during three conditions (baseline, immediate response to vibro-acoustic stimulation (VAS), and post-response). Design: A prospective, longitudinal design was utilized. Subjects: Twelve normally developing fetuses, eight females and four males, were examined with continuous ultrasound imaging. Outcome Measures: The fetal neurobehavioral coding system (FENS) was used to evaluate the quality of motor activity during 10-s epochs over the three conditions. Results: Seventy-five percent of the fetuses at the 26-week assessment and $100 \%$ of the fetuses at the 36 -week assessment responded with movement immediately following stimulation. Significant differences in head, fetal breathing, general, limb, and mouthing movements were detected between the 26 and 36-week assessments. Movement differences between conditions were detected in head, fetal breathing, limb, and mouthing movements. Conclusion: Smoother and more complex movement was observed with fetal maturation. Following VAS stimulation, an immediate increase of large, jerky movements suggests instability in fetal capabilities. Fetal movement quality changes over gestation may reflect sensorimotor synaptogenesis in the central nervous system, while observation of immature movement patterns following VAS stimulation may reflect movement pattern instability.
\end{abstract}

Keywords: motor development, fetal programming, prenatal, pregnancy, fetal movement

\section{INTRODUCTION}

Assessment of motor development in the human fetus provides an opportunity to examine maturation of the central nervous system during gestation (Kostovic and Goldman-Rakic, 1983; Kostovic and Rakic, 1984; Kostović et al., 1995; DiPietro et al., 1996). During the third trimester, neuronal differentiation and synaptogenesis flourish in the cortical plate with afferent projections from the thalamus migrating deeper into the cortical layer (Kostovic and Rakic, 1984; Kostović et al., 1995, 2002) increasing the probability that movement will be generated and modified in response to stimulation. Maturation and formation of additional sensorimotor connections in the cortex may create detectable changes in fetal movement as a product of improved sensory feedback (Khazipov et al., 2004; Milh et al., 2007; Hanganu-Opatz, 2010).

The limited literature available evaluating fetal movement utilizes a variety of examination methods to chronicle development over gestation and the movements documented vary depending on gestational age at observation and the movement classification system employed. Fetal movement recorded with continuous ultrasound suggests that some general movements, such as fetal breathing and mouth movements, increase, whereas other movements, such as startles, decrease with advancing gestational age (deVries et al., 1985; Roodenberg et al., 1991; D’Elia et al., 2001). Assessments of movement quality in addition to specific movement type, will improve the ability to detect developmental trends in movement over gestation and may provide evidence of neurological maturation and motor learning in the fetus.

Vibro-acoustic stimulation (VAS) applied over the maternal abdomen has been used to detect when during gestation a fetus is capable of producing a motor response (Gagnon et al., 1987; Kisilevsky et al., 1992; van Heteren et al., 2000). Depending on how long the fetus was observed after stimulation, motor responses have been observed in fetuses between 26 to 33-gestational weeks (Gagnon et al., 1987; Kisilevsky et al., 1992; van Heteren et al., 2000). Previous studies utilizing fetal ultrasound have classified movement as a change in fetal activity, with only two studies examining specific movement type or quality; one documenting the occurrence of the startle reflex (Groome et al., 1995); 
and one documenting eye and mouthing movements (Morokuma et al., 2004). Improved understanding of the quality of movements occurring following VAS stimulation may provide additional insight into not only the ability of the fetus to react, but also the quality and stability of motor skills.

The fetal neurobehavioral coding system (FENS) has been developed to examine fetal movement and behavior via ultrasound over gestation (Salisbury et al., 2005). The FENS distinguishes between small and large, jerky and smooth, regular and irregular movements, as well as head extension and rotation, which may document fetal maturation. For instance, smooth and regularly occurring movements indicate maturation of motor coordination and head rotation requiring coordination of ipsilateral flexion, and contralateral extension muscles in the neck in contrast to more immature patterns of bilateral unilateral contraction as found in head extension. By examining subtle changes to specific fetal movements over gestation, these changes in quality of fetal movements may reflect cortical synaptogenesis, migration of thalamic neurons into the cortical layers, and changes in cortical white matter.

The purpose of the present investigation was to evaluate developmental changes in the organization of fetal movement using a prospective, longitudinal design. Fetal movement patterns in response to VAS were assessed at 26 and 36-weeks gestational age during three conditions (baseline, immediate response, and post-response). Based on research documenting increased sensory motor connections and motor learning concepts, we hypothesized that with maturation more coordinated, smooth movements will be observed. Further, primitive movement patterns will increase following a novel, intense stimulation. This study is the first to assess developmental changes in the quality of fetal movements and distinguish between large and small limb movements to illuminate the formation and maturation of sensorimotor connections in the central nervous system.

\section{MATERIALS AND METHODS}

Using a prospective, longitudinal design, maturational changes in fetal motor development were assessed in 12 fetuses at 26 and 36 gestational weeks.

\section{SUBJECTS}

Adult women pregnant with a singleton intrauterine pregnancy were recruited from the University of California, Irvine Medical Center located in Orange, CA, USA. Twelve pregnant women were enrolled in the study who met the following inclusion criteria: (1) normal uterus and placenta, (2) English speaking, (3) non-smokers and no drug use, (4) no major medical conditions. Maternal mean age was 26.8 years (range of 19-41 years). Sixtyseven percent of the women reported ethnicity as non-Hispanic white with $33 \%$ reporting as Hispanic. Fifty percent of the women were primiparous. Fetuses were $67 \%$ female and $33 \%$ male. This study was approved by the University of California - Irvine Institutional Review Board and all participants signed informed consent prior to data collection.

\section{EQUIPMENT AND MEASUREMENT TOOLS}

An ATL diagnostic ultrasound machine, Model Ultramark 400c, with a $3.50 \mathrm{MHz}$ transducer (Advanced Technology Laboratories,
Bothell, WA, USA) was used to record fetal movement. One ultrasound transducer was used to visualize the face, chest, and upper limbs. The research nurse, certified as a sonographer, focused the transducer to maintain a continuous, longitudinal view of the fetal face and chest.

A general electric fetal acoustic stimulator (FASt) model 146 was used to provide VAS to each fetus. The VAS head was $15.2 \mathrm{~cm}$ in length, $4.6 \mathrm{~cm}$ in width, and $5.6 \mathrm{~cm}$ in depth with a weight of $227 \mathrm{~g}$. Following a baseline period, a $75 \mathrm{~Hz}, 82 \mathrm{~dB}$ VAS was produced for $3 \mathrm{~s}$. It was positioned on the maternal abdomen near the fetal back following visualization with the ultrasound.

\section{PROCEDURE}

Mothers attended two sessions, one at 26 to 28 -weeks' gestation (mean gestational age $=26.63$ weeks, $S D=0.46)$ and one at 36 to 38 -weeks' gestation (mean gestational age $=36.48$ weeks, $\mathrm{SD}=0.65$ ), for data collection. Complete data were collected from all maternal/fetal pairs. At each visit, an identical fetal monitoring procedure was administered. During testing, mothers were positioned on a standard, padded examination table in a low semi-fowlers position (5-10 tilt). Headphones were placed on the mother to provide pure tone music during the entire fetal examination to mask extraneous noise and the auditory component of the stimulation. Prior to the fetal assessment procedure the mothers were seated in a comfortable reclining armchair and asked to sit quietly and relax for $20 \mathrm{~min}$. An ultrasound transducer was used to record fetal behavior, fetal biometry, placental location, and amniotic fluid volume. Fetal state was not determined secondary to lack of fetal heart rate monitoring. All fetuses had normal amniotic fluid index measurements at all data collection periods. Fetal weight determined with ultrasound biometry was within $10-90 \%$ for all fetuses during both measures, except one fetus that dipped below the $10 \%$ level at 26 weeks, but was above the $10 \%$ level at 36 weeks.

Fetal monitoring began with a 6-min baseline (resting) recording of fetal longitudinal head and chest visualization. Administration of a 3-s VAS signal was delivered to the mother's abdomen following absence of general body movements in the fetus for $30 \mathrm{~s}$. Ultrasound observation continued for a $30 \mathrm{~s}$ immediate response and $4 \mathrm{~min}$ and $20 \mathrm{~s}$ post-response period.

\section{CODING OF FETAL BEHAVIOR}

The FENS (Salisbury et al., 2005) was used to score the digital ultrasound images. Ultrasound images were viewed and scored using Mangold Interact Software (Germany) to code the following behaviors; head movements (extension, isolated, rotation), fetal breathing movements (regular, irregular, vigorous, hiccup), general body movements (backarch, startle, smooth general body movements, jerky general body movements, stretch), limb movements (large, jerky; large, smooth; small, jerky; small, smooth, hand to face), and mouthing movements (non-rhythmic, rhythmic, yawn). Scoring was completed in two passes of image viewing by a single trained coder. Following image inspection for quality of the image, the first pass on the images was used to code movements and behaviors of the face and head including, head movements, mouthing, and yawning. During the second pass on the images, specific movements and behaviors of the chest and body were coded, including the quality of the movements, 
jerky, or smooth. Specific movements including, fetal breathing movements, startles, back arch, stretch, and hiccup, were scored whenever present. The three study periods (baseline, immediate response, and post-response) were divided into 10-s epochs. Each behavior was scored as either present or absent during each 10-s epoch. Twenty percent $(N=5)$ of the recordings in this sample were randomly selected and coded by an independent observer to assess inter-rater reliability, intraclass correlation coefficients of $0.72-1.0$ were obtained with percent agreement of $76-100 \%$ for individual behaviors. Inter-rater reliability for the present sample was consistent with reliability values reported in prior work by our group (Salisbury et al., 2005).

\section{DATA ANALYSIS}

Data were analyzed to address the following questions:

1. How many fetuses demonstrated a motor response during the $30 \mathrm{~s}$ immediate post VAS stimulation (immediate response) at 26 and 36 weeks? The number of fetuses at 26 and 36 gestational weeks who responded to the VAS with any movement during the immediate response period was reported and a Chisquare was used to evaluate the immediate response frequencies between the 26 and 36-week assessment.

2. Did movement differ by gestational age or in response to the VAS? The total number of 10-s epochs spent exhibiting each movement was determined for the baseline, immediate response, and post-response periods. To determine if the observed movements differed by assessment age (26 versus 36-weeks gestation) or period (baseline, immediate response, post-response), two (age) by three (period) repeated measures ANOVAs were computed first for five general patterns of body movement; head movements (consisting of rotation, extension, and isolated head movements), fetal breathing movements (consisting of irregular, regular, and vigorous fetal breathing movements), mouthing movements (consisting of rhythmic and non-rhythmic mouthing movements), and limb movements (consisting of large and small, smooth and jerky limb movements) and then for each specific behavior individually. If the ANOVA was significant, Chi-square tests were used to evaluate changes in movement quality across assessment age and period. Only those general categories or specific movements, which demonstrated differences between gestational age or period, are reported.

\section{RESULTS}

\section{IMMEDIATE MOTOR RESPONSES TO THE VAS}

Seventy-five percent (9/12) of the fetuses at the 26 gestational week assessment and $100 \%$ of the fetuses at the 36 gestational week assessment displayed a recorded movement during the immediate response period. All fetuses, at both assessments, who demonstrated movement within the immediate response period, demonstrated their first movements within $20 \mathrm{~s}$. Chi-square results support a significant higher likelihood of immediate motor response at the 36-week assessment as compared to the 26-week assessment $\left[\chi^{2}{ }_{(1)}=120.65, p<0.001\right]$. Of the movements demonstrated in the immediate response period, limb movements occurred in eight out of nine fetuses $(88.8 \%)$ at the 26 -week assessment and
10 out of 12 fetuses $(83.3 \%)$ at the 36 -week assessment. Head movements occurred in six out of nine fetuses $(66.7 \%)$ at the 26-week assessment and seven out of 12 fetuses (58.3\%) at the 36week assessment. Startles were observed in zero of the fetuses at the 26-week assessment $(0 \%)$ and one fetus at the 36-week assessment $(8 \%)$. Three fetuses at the 26-week assessment (25\%) demonstrated a general body movement (two jerky and one smooth) and one fetus at the 36-week assessment (8\%) demonstrated a smooth general body movement during the immediate response period.

\section{MEAN PERCENTAGE OF TIME PERFORMING EACH BEHAVIOR AT EACH AGE IN EACH PERIOD}

Percentage of epochs performing each specific movement is shown in Figures 1-5 for each condition (baseline, immediate response, and post-response) and for each assessment age (26 and 36-gestational weeks).

\section{Head movements}

Total head movements were observed for a similar number of epochs at the 26 and 36-week assessments $\left[F_{(1,11)}=2.83\right.$, $p=0.121$; Figure 1], however, the type of head movement differed by gestational age. Significantly more head rotations were observed at the 36-week assessment $\left[F_{(1,11)}=6.31, p=0.030\right]$. At both 26 and 36 gestational weeks, total head movements were observed more frequently during the immediate response period (22.2\% epochs at 26 weeks and $33.3 \%$ epochs at 36 weeks) compared to baseline period $[12.5 \%$ of the epochs at 26 weeks and $13.9 \%$ of the epochs at 36 weeks; $\left.F_{(2,22)}=3.71, p=0.041\right]$.

\section{Fetal breathing movements}

Total $\left[F_{(1,11)}=8.92, p=0.012\right]$, regular $\left[F_{(1,11)}=5.32, p=0.042\right]$, and irregular $\left[F_{(1,11)}=8.34, p=0.015\right]$ fetal breathing movements were greater at the 36 -week assessment compared to the 26-week assessment (Figure 2). At both assessment ages, a decrease in regular fetal breathing was observed in the immediate response

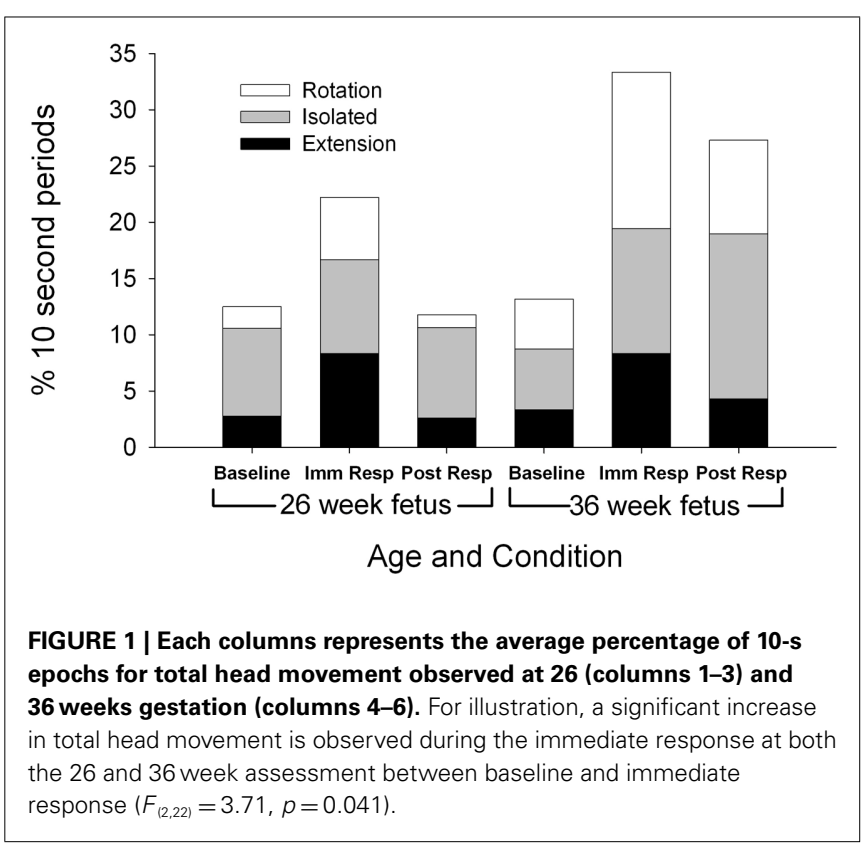




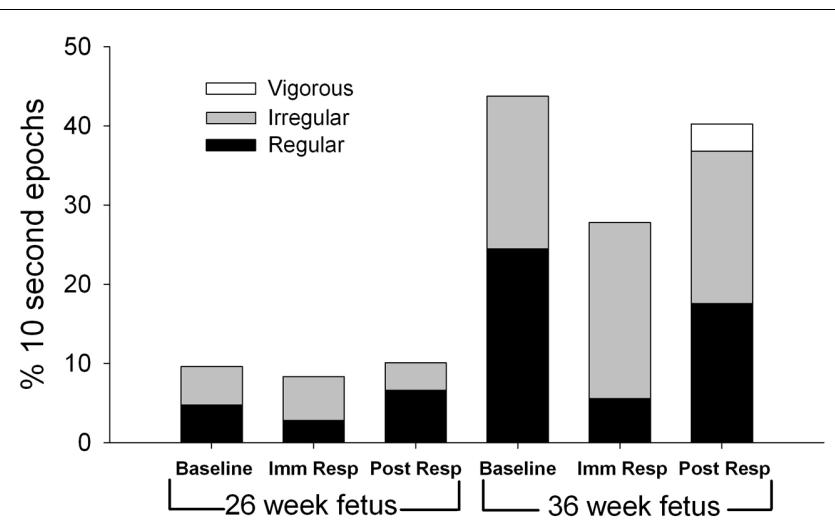

Age $\times$ Condition

FIGURE 2 | Each column represents the average percentage of 10-s epochs for breathing movements (regular, irregular, and vigorous) and hiccups observed at 26 (columns 1-3) and 36 weeks gestation (columns 4-6). For illustration, regular fetal breathing movements (white) demonstrated an interaction with a decrease in movements during the immediate response period at the 36 week assessment with no difference between baseline and immediate response observed at the 26 week assessment $\left(F_{(1,11)}=4.46, p=0.027\right)$.

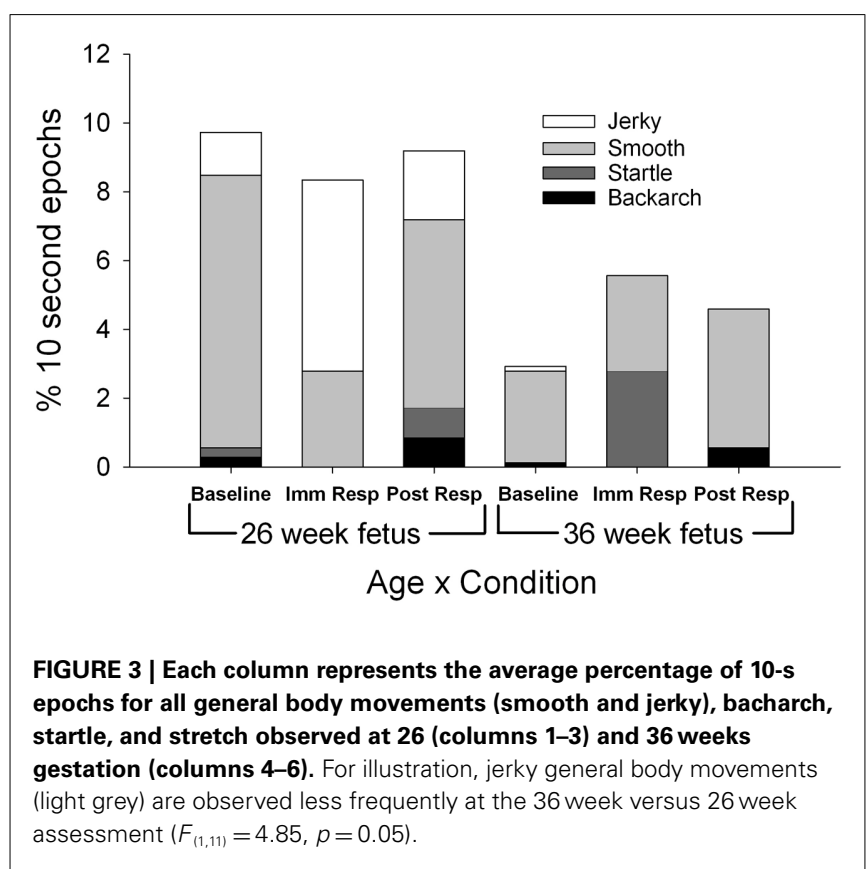

period compared to the baseline period $\left[F_{(2,22)}=4.76, p=0.024\right]$. The age by period interaction was also significant for regular fetal breathing $\left[F_{(1,11)}=4.46, p=0.027\right]$. Immediately after the VAS, the fetuses at the 36-week assessment decreased regular fetal breathing movements $\left[t_{(11)}=3.36, p=0.006\right]$, however, no significant difference was observed between baseline and immediate response in the fetuses at the 26-week assessment $\left[t_{(11)}=0.77\right.$, $p=0.46]$. Irregular fetal breathing movements demonstrated no significant differences between periods $\left[F_{(2,22)}=0.174, p=0.84\right]$
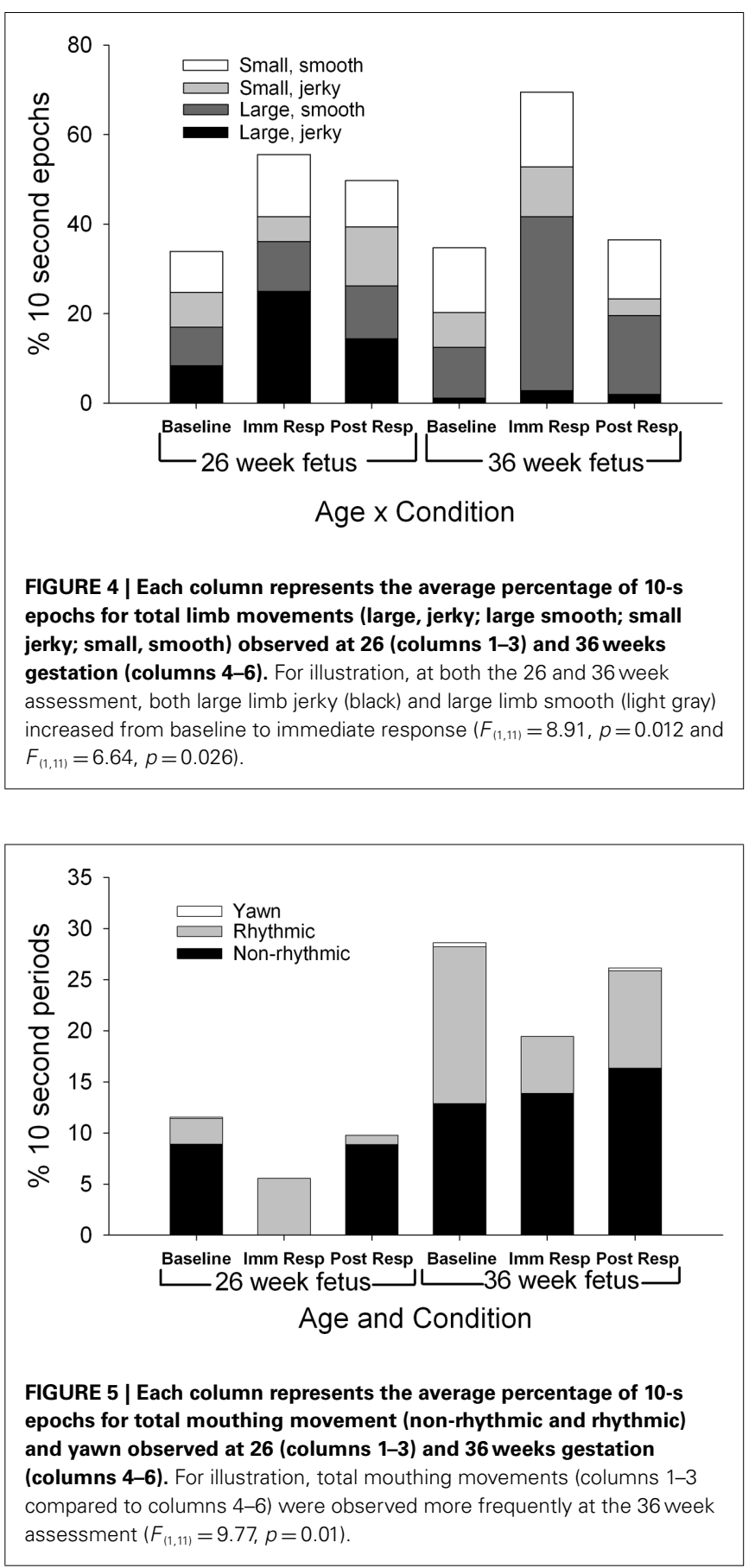

and no age $\times$ period interaction $\left[F_{(2,22)}=0.020, p=0.94\right]$. In the fetuses at the 36-week assessment, the ratio of regular to irregular breathing was 56:44 (regular to irregular) at baseline with a shift to 20:80 (regular to irregular) during the immediate response period $\left[\chi^{2}{ }_{(1)}=27.5, p<0.001\right]$. At the 26-week assessment, the ratio of regular to irregular had a smaller shift from the baseline level (49:51 regular to irregular) to the immediate response level [33:67 regular to irregular; $\chi^{2}{ }_{(1)}=5.3, p=0.02$ ]. In addition, vigorous fetal breathing movements were only observed at the 36-week assessment during the post-response period. 


\section{General body movements}

Fetuses demonstrated fewer total general body movements (sum of smooth and jerky) at the 36-week assessment $\left[F_{(1,11)}=5.51\right.$, $p=0.039$; Figure 3], with jerky, general body movements observed statistically less frequently at the 36-week assessment $\left[F_{(1,11)}=4.85, p=0.05\right]$. At the 26-week assessment, the ratio of smooth to jerky general body movements shifted from 86:14 (smooth to jerky) at baseline to 33:67 (smooth to jerky) at immediate response $\left[\chi^{2}{ }_{(1)}=58.67, p<0.001\right]$. The immediate response (33:67 smooth to jerky) to post-response ratio (73:27 smooth to jerky) demonstrated a shift back to more smooth versus jerky general movements $\left[\chi^{2}(1)=31.8, p<0.001\right]$.

\section{Limb movements}

Specific limb movements revealed two main effects for age (Figure 4). More jerky, large limb movements were observed in the fetuses at the 26-week assessment $\left[F_{(1,11)}=8.91, p=0.012\right]$ and more smooth, large limb movements were observed in the fetuses at the 36-week assessment $\left[F_{(1,11)}=6.64, p=0.026\right]$. Limb movements increased during the immediate response period $\left[F_{(2,22)}=6.75, p=0.01\right]$ with both large limb, jerky and large limb, smooth increased significantly over the baseline levels for fetuses at both assessment ages $\left[F_{(1,11)}=8.91, p=0.012\right.$ and $\left.F_{(1,11)}=6.64, p=0.026\right]$. During the baseline period, two specific limb relationships were observed between the fetuses at the 26-week assessment and the fetuses at the 36-week assessment. First, during the 26-week assessment, fetuses demonstrated an equal 50:50 large to small limb movement ratio compared to the increase in more specific, small limb movements (36:64 large to small ratio) demonstrated at the 36-week assessment $\left[\chi^{2}(1)=4.0\right.$, $p<0.045]$. Secondly, the smooth, large limb movement increased in relation to jerky, large limb movements as the fetus aged [51:49 ratio at the 26-week assessment and 91:9 ratio at the 36 week assessment; $\left.\chi^{2}{ }_{(1)}=38.9, p<0.001\right]$. Two differences in limb movement quality ratios were also observed between periods. At the 26-week assessment, the ratio between large smooth and large jerky limb movements shifted from similar amounts of smooth to jerky at baseline (51:49 smooth to jerky) to an increase ratio of jerky at immediate response [31:69 smooth to jerky; $\chi^{2}{ }_{(1)}=8.3$, $p=0.004]$. The ratio of large limb to small limb movements demonstrated a shift at the 36-week assessment between baseline (36:64 large to small) to immediate response [60:40 large to small; $\left.\chi^{2}(1)=11.5, p<0.001\right]$.

\section{Mouthing movements (Figure 5)}

As shown in Figure 5, total mouthing movements (rhythmic and non-rhythmic) occurred more frequently at the 36 week assessment $\left[F_{(1,11)}=9.77, p=0.01\right]$, with non-rhythmic mouthing observed more at the 36 week assessment than the 26-week assessment $\left[F_{(1,11)}=8.91, p=0.012\right]$. During baseline, fetuses at the 26-week assessment demonstrated a 22:78 rhythmic to nonrhythmic ratio compared to a higher ratio of rhythmic mouthing (54:46 rhythmic to non-rhythmic) at the 36 week assessment $\left[\chi^{2}{ }_{(1)}=21.7, p<0.001\right]$. During the post-response period, fetuses at the 26-week assessment demonstrated a large ratio, 9:91, of rhythmic to non-rhythmic mouthing that decreased to $37: 63$ ratio of rhythmic to non-rhythmic mouthing at the 36 week assessment $\left[\chi^{2}{ }_{(1)}=22.1, p<0.001\right]$. At the 36-week assessment, a ratio difference between rhythmic and non-rhythmic mouthing movements was observed between the baseline (54:46 rhythmic to non-rhythmic) and immediate response (29:71 rhythmic to non-rhythmic) periods $\left[\chi^{2}(1)=13.5, p<0.001\right]$.

\section{DISCUSSION}

The results indicate that: (1) graded movements became more complex and coordinated over gestation, and (2) VAS stimulation resulted in an increase in large, more robust, possibly immature, movements at both gestational ages. Specifically, we observed an increased percentage of smooth, regular, and more complicated flexion and extension pattern movements in every movement category examined during baseline at 36-weeks gestation compared to 26-weeks gestation. In response to the challenge of the VAS, both gestational ages demonstrated an increase in large, jerky, or irregular movements in comparison to the baseline period. With neurological maturation including axonal development of white matter (Girard et al., 1995; Hayes et al., 2005), fetal movement may become more specific and coordinated, but when faced with intense or novel stimulation, movement appears to revert to large, more immature movement patterns. Both of these changes support the need to observe specific movements over age and during the introduction of unique environmental stimulation in order to assess sensorimotor maturation.

\section{IMMEDIATE MOTOR RESPONSES TO THE VAS}

We documented a higher percentage of fetuses at the 26-week assessment (75\%) moving after the VAS stimulation than found in previous research. Kisilevsky et al. (1992) reported that $58 \%$ of fetuses 26 to 28 -weeks gestation and $92-100 \%$ of fetuses 32 to 36 -weeks gestation responded within $5 \mathrm{~s}$ post VAS with a cross sectional view of the fetal trunk which may or may not have included limbs. Examination of the whole body, including head and arm movement with utilization of the FENS scoring system, resulted in observing a higher incidence of fetal movement after the VAS. Our data suggest that a large percentage of the movement observed in the first $20 \mathrm{~s}$ immediately following VAS stimulation included limb and head movements and may reflect a functional motor response to novel and intense stimulation. Movement of the head may promote visual location of the stimuli and use of the limbs may be utilized to protect the fetus.

Both Gagnon et al. (1987) and Park et al. (2010) suggest that fetal movement is a product of subcortical activation and thus, are more reflexive responses to vibratory input. While Gagnon did examine specific fetal movement via ultrasound with the methodology that responses were different types of startle, Park et al. (2010) documented fetal movement via maternal detection in anencephalic fetuses, which is an indirect measure. The fetuses in this study demonstrated a large variety of movement combinations in response to VAS stimulation, which is inconsistent with a simple reflexive response. A third option to either subcortical or cortical activation includes the theory that activation of subcortical structures are modified by cortical structures when stimulations is present. In order to explore whether subcortical activation is modified by cortical input, examination of specific fetal movements via ultrasound in fetuses with and without cortical input would be required to detect if specific movements are altered or modified by cortical input. 


\section{MOVEMENT DIFFERENCES BETWEEN 26 AND 36 WEEKS}

Changes in the pattern of fetal movement between the 26 and 36 gestational week assessment support the argument that movement becomes more precise and coordinated as the fetus ages. At the younger assessment, bilateral agonist (head extension and back arch) muscle activation was observed with higher frequency. With advancing gestational age, an increase in contralateral agonist and antagonist (head rotation) was observed. This suggests that muscle activation becomes more coordinated later in gestation. The decrease in general body movements and increase in limb movements with advancing gestation suggests movements become more precise or specific to isolated areas of the body. This decrease in general body movements may also be influenced by a decrease in uterine space inherent in advancing gestational age. In addition, the decrease in jerky movements and increase in smooth movement across gestation suggests that the fetus may have a greater ability to coordinate movement with development of increased sensory connections to the motor system. The overall increase in fetal breathing movement from 26 to 36-weeks gestation is consistent with previous research (Gagnon et al., 1987; Marks et al., 1995) and may be related to lung maturation. As the fetus matures, a larger frequency of rhythmical breathing and mouthing was observed, which may be an important precursor to the rhythmical coordination between breathing and sucking required for feeding while breathing after birth.

\section{MOVEMENT DIFFERENCES BETWEEN BASELINE, IMMEDIATE RESPONSE, AND POST-RESPONSE PERIODS}

Comparison of movement between the baseline, immediate response, and post-response period suggests that after intense stimulation movement regresses to patterns observed earlier in gestation. The increase in head movement and large limb movements from baseline to immediate response period at both gestational ages suggests these movements compose a large portion of the movement response to this novel stimulus, while the decrease in regular fetal breathing indicates a cessation of this activity in response to novel stimulation. Head movements in response to a startling and intense stimulation may increase visual localization of the stimuli, while limb movements may be useful for protection. Fetal breathing movements promote lung development, but are not as vital to the fetus during times of stress. In addition to the increases in specific large movements, an increase in jerky, irregular, and non-rhythmic movements were observed which might signal motor immaturity and a startle in the fetus. Use of more immature, larger movements following VAS stimulation in the fetus supports the prediction that with a novel, unexpected stimulation, the fetus will revert to patterns of movements observed at earlier stages of development. Movement regression post VAS stimulation may reflect a lack of motor experience with the newer learned movements and the emergence of older movement patterns that are more stable with stronger neurological connections. This display of immature patterns following VAS stimulation is consistent with the Dynamic Systems perspective that more rehearsed, stable patterns of behavior versus newer, emerging patterns of behavior will be observed during novel situations (Heriza, 1991).

\section{LIMITATIONS}

One limitation of the present study design is the scoring of fetal movement as present or absent during 10-s epochs. Future work would benefit from the continuous evaluation of fetal movement to allow for the additional evaluation of coordination of fetal movement responses. However, continuous observation of specific movements during 10-s intervals is a significantly higher temporal resolution than has been included in previous observations of fetal movement in response to VAS (Gagnon et al., 1987; Kisilevsky et al., 1992; van Heteren et al., 2001). Further, the current study included comprehensive assessments of fetal behaviors at baseline and in response to a standardized challenge (VAS).

Inclusion of 12 subjects in the current study may be viewed as a limitation. While more subjects may have provided more statistical power, 12 subjects did provide the power necessary to distinguish statistical differences between 26 and 36 weeks on a variety of movements. The statistical differences found also suggest that the effect size for movement differences is large enough to be highlighted utilizing a small number of subjects.

\section{FUTURE RESEARCH}

This study adds new information regarding motor development during the fetal period, however, observation of fetal movement utilizing the FENS during a broader range of gestation weeks with more subjects will highlight movement development issues not observed in this present study. In addition, assessment of fetal motor development across gestation with the documentation of endocrine influences may highlight influence of the maternal system on fetal neurological systems and subsequent development (DiPietro et al., 1996, 2009; Sandman et al., 1999, 2003; Davis and Sandman, 2006; Davis et al., 2007; Class et al., 2008). Sex differences in fetal motor maturation should be examined (Bernardes et al., 2008; Buss et al., 2009) in light of recent differences documented in fetal HR maturation between sexes. Additional information regarding motor control and learning in the fetus, including variables that influence the motor system, will improve the clinicians' ability to identify at risk fetuses for continued monitoring and intervention post birth.

\section{CONCLUSION}

The development of more complex movements as the fetus ages is an important indicator of motor development and may signal neurological development and motor learning. As the fetus ages, our data suggest movement becomes more complex and coordinated. However, during periods of intense stimulation, such as the VAS, fetal movements are characterized by higher frequencies of more immature and uncoordinated movement patterns. Based on our data, changes in fetal movement at different ages and following VAS appear to be part of the normal maturational process. With further research supporting of these findings, a specific assessment utilizing these motor differences may be useful at the clinical level to document neurological maturation.

\section{ACKNOWLEDGMENTS}

This research was supported by awards from the NIH to Curt A. Sandman (HD-51852 and NS-41298). The authors wish to thank the families who participated in this project. The assistance of Cheryl Crippen and Christina Canino of the Women and Children's Health and Well-Being Project, Department of Psychiatry and Human Behavior, University of California is gratefully acknowledged. 


\section{REFERENCES}

Bernardes, J., Goncalves, H., Ayresde-Campos, D., and Rocha, A. P. (2008). Linear and complex heart rate dynamics vary with sex in relation to fetal behavioural states. Early Hum. Dev. 84, 433-439.

Buss, C., Davis, E. P., Class, Q. A., Gierczak, M., Pattillo, C., Glynn, L. M., and Sandman, C. A. (2009). Maturation of the human fetal startle response: evidence for sex-specific maturation of the human fetus. Early Hum. Dev. 85, 633-638.

Class, Q. A., Buss, C., Davis, E. P., Gierczak, M., Pattillo, C., Chicz-DeMet, A., and Sandman, C. A. (2008). Low levels of corticotrophin-releasing hormone during early pregnancy are associated with precocious maturation of the human fetus. $\mathrm{Dev}$. Neurosci. 30, 419-426.

Davis, E. P., Glynn, L. M., Schetter, C. D., Hobel, C., Chicz-DeMet, A., and Sandman, C. A. (2007). Prenatal exposure to maternal depression and cortisol influences infant temperament. J. Am. Acad. Child. Adolesc. Psychiatry 46, 737-746.

Davis, E. P., and Sandman, C. A. (2006). Prenatal exposure to stress and stress hormones influences child development. Inf. Young Children 19, 246-259.

D’Elia, A., Pighetti, M., Moccia, G., and Santangelo, N. (2001). Spontaneous motor activity in normal fetuses. Early Hum. Dev. 65, 139-147.

deVries, J., Visser, G., and Prechtl, H. (1985). The emergence of fetal behaviour. II. Quantitative aspects. Early Hum. Dev. 12, 99-120.

DiPietro, J., Hodgson, D., Costigan, K., Hilton, S. and Johnson, X. (1996). Fetal neurobehavioral development. Child Dev. 67, 2553-2567.

DiPietro, J., Kivlighan, K., Costigan, K., and Laudenslager, M. (2009). Fetal motor activity and mateanal cortisol. Dev. Psychobiol. 51, 505-512.

Gagnon, R., Hunse, C., Carmichael, L., Fellows, F., and Patrick, J. (1987).
Human fetal responses to vibratory acoustic stimulation from twentysix weeks to term. Am. J. Obstet. Gynecol. 157, 1375-1381.

Girard, N., Raybaud, C., and Poncet, M. (1995). In vivo MR study of brain maturation in normal fetuses. Am. J. Neuroradiol. 16, 407-413.

Groome, L., Singh, K., Burgard, S., Neely, C., and Deaton, M. (1995). Motor responsivity during habituation testing of normal human fetuses. J. Perinat. Med. 23, 159-166.

Hanganu-Opatz, I. (2010). Between molecules and experience: role of early patterns of coordinated activity for the development of cortical maps and sensory abilities. Brain Res. Rev. 64, 160-176.

Hayes, R. L., Borenstein, N. S., Desilva, T. M., Folkerth, R. D., Liu, L. G., Volpe, J. J., and Kinney, H. C. (2005). Axonal development in the cerebral white matter of the human fetus and infant. J. Comp. Neurol. 484, 156-167.

Heriza, C. (1991). Implications of dynamic systems approach to understanding infant kicking behavior. Phys. Ther. 71, 222-235.

Khazipov, R., Sirota, A., Leinekugel, X., Holmes, G., and Ben-Ari Y Buzsaki, G. (2004). Early motor activity drives spindle bursts in the developing somatosensory cortex. Nature 432, 758-761.

Kisilevsky, B. S., Muir, D. W., and Low, J. A. (1992). Maturation of human fetal responses to vibroacoustic stimulation. Child Dev. 63, 1497-1508.

Kostovic, I., and Goldman-Rakic, P. (1983). Transient cholinesterase staining in the nediodorsal nucleus of the thalamus and its connections in the developing human and monkey brain. J. Comp. Neurol. 219, 431-447.

Kostović, I., Judas, M., Petanjek, Z., and Simic, G. (1995). Ontogenesis of goal-directed behavior: anatomo-functional considerations.
Int. J. Psychophysiol. 19, 85-102.

Kostović, I., Judaš, M., Radoš, M., and Hrabač, P. (2002). Laminar organization of the human fetal cererum revealed by histochemical markers and magnetici resonance imaging. Cereb. Cortex 12, 536-544.

Kostovic, I., and Rakic, P. (1984). Development of prestriate visual projections in the monkey and human fetal cerebrum revealed by transient cholinesterase staining. J. Neurosci. 4, 25-42.

Marks, F., Zimmer, E., Chao, C., Monteagudo, A., and Fox, H. (1995). Vibratory acoustic stimulation and fetal gasping. J. Reprod. Med. 40, 513-515.

Milh, M., Kaminska, A., Huon, C., Lapillonne, A., Ben-Ari, Y., and Khazipov, R. (2007). Rapid cortical oscillations and early motor activity in premature human neonate. Cereb. Cortex 17, 1582-1594.

Morokuma, S., Fukushima, K., Kawai, N., Tomonaga, M., Satoh, S., and Nakano. H. (2004). Fetal habituation correlates with functional brain development. Behav. Brain Res. 153, 459-463.

Park, Y. J., Park, S. H., Kim, Y. J., Hoh, J. K., Park, Y. S., and Park. M. I. (2010). Computerized fetal heart rate monitoring after vibroacoustic stimulation in the anencephalic fetus. Early Hum. Dev. 86, 569-572.

Roodenberg, P., Wladimiroff, J., vanes, A., and Prechtl, H. (1991). Classification and quantitative aspects of fetal movements during the second half of normal pregnancy. Early Hum. Dev. 25, 19-35.

Salisbury, A. L., Duncan Fallone, M., and Lester, B. (2005). Neurobehavioral assessment from fetus to infant: the NICU network neurobehavioral scale and the fetal neurobehavior coding scale. Ment. Retard. Dev. Disabil. Res. Rev. 11, 14-20.

Sandman, C. A., Glynn, L., Wadhwa, P. D., Chicz-DeMet, A., Porto,
M., and Garite, T. (2003). Maternal HPA disregulation during the third trimester influences human fetal behavior. Dev. Neurosci. 25, 41-49.

Sandman, C. A., Wadhwa, P. D., ChiczDeMet, A., Porto, M., and Garite, T. J. (1999). Maternal corticotrophinreleasing hormone and habituation in the human fetus. Dev. Psychobiol. 34, 163-173.

van Heteren, C. F., Boekkooi, P. F., Jongsma, H. W., and Nijhuis, J. G. (2000). Fetal learning and memory. Lancet 356, 1169-1170.

van Heteren, C. F., Boekkooi, P. F., Jongsma, H. W., and Nijhuis, J. G. (2001). Fetal Habituation to vibroacoustic stimulation in relation to fetal states and fetal heart rate parameters. Early Hum. Dev. 61 135-145.

Conflict of Interest Statement: The authors declare that the research was conducted in the absence of any commercial or financial relationships that could be construed as a potential conflict of interest.

Received: 10 June 2011; accepted: 08 November 2011; published online: 21 December 2011.

Citation: Grant-Beuttler M, Glynn LM, Salisbury AL, Davis EP, Holliday C and Sandman CA (2011) Development of fetal movement between 26 and 36-weeks' gestation in response to vibro-acoustic stimulation. Front. Psychology 2:350. doi: 10.3389/fpsyg.2011.00350

This article was submitted to Frontiers in Developmental Psychology, a specialty of Frontiers in Psychology.

Copyright (C) 2011 Grant-Beuttler, Glynn, Salisbury, Davis, Holliday and Sandman. This is an open-access article distributed under the terms of the Creative Commons Attribution Non Commercial License, which permits non-commercial use, distribution, and reproduction in other forums, provided the original authors and source are credited. 